\title{
Eribulin Promotes Antitumor Immune Responses in Patients with Locally Advanced or Metastatic Breast Cancer
}

\author{
WATARU GOTO ${ }^{1}$, SHINICHIRO KASHIWAGI ${ }^{1}$, YUKA ASANO ${ }^{1}$, KOJI TAKADA ${ }^{1}$, \\ TAMAMI MORISAKI ${ }^{1}$, HISAKAZU FUJITA ${ }^{2}$, TSUTOMU TAKASHIMA ${ }^{1}$, \\ MASAHIKO OHSAWA ${ }^{3}$, KOSEI HIRAKAWA ${ }^{1}$ and MASAICHI OHIRA ${ }^{1}$ \\ ${ }^{1}$ Department of Surgical Oncology, Osaka City University Graduate School of Medicine, Osaka, Japan; \\ ${ }^{2}$ Department of Scientific and Linguistic Fundamentals of Nursing, \\ Osaka City University Graduate School of Nursing, Osaka, Japan; \\ ${ }^{3}$ Department of Diagnostic Pathology, Osaka City University Graduate School of Medicine, Osaka, Japan
}

\begin{abstract}
Background/Aim: Several proteins involved in immune regulation and the relationship among these, the tumor microenvironment, and clinical outcomes of eribulin treatment were evaluated in advanced or metastatic breast cancer patients. Patients and Methods: This retrospective cohort study comprised 52 eribulin-treated locally advanced or metastatic breast cancer patients. Cancer tissue samples were obtained before and after treatment in 10 patients. Immunohistochemistry was performed to determine programmed death (PD)-1, CD8, and forkhead box P3 (FOXP3) expression by stromal tumorinfiltrating lymphocytes, and PD-ligand (L1) and PD-L2 expression by cancer cells. Results: Of the 10 patients, 5 were responders (partial response) and 5 were non-responders (stable disease, 2; progressive disease, 3) to eribulin. PD-1, $P D-L 2$, and FOXP3 expression became negative in 5 patients, $P D-L 1$ expression became negative in 6 patients, and CD8 expression became positive in 3 patients after treatment. The response to eribulin was significantly associated with $P D-L 1$ and FOXP3 negative conversion ( $p=0.024$ and 0.004, respectively). The change in E-cadherin expression (positive or negative) was also correlated with the changes in PD-L1 and FOXP3 ( $p=0.024$ and 0.004, respectively). Kaplan-Meier analysis with log-rank tests revealed that progression-free survival and time-to-treatment failure were significantly longer in patients with PD-L1 and FOXP3 negative conversion
\end{abstract}

This article is freely accessible online.

Correspondence to: Shinichiro Kashiwagi, MD, Ph.D., Osaka City University Graduate School of Medicine, 1-4-3 Asahi-machi, Abeno-ku, Osaka 545-8585, Japan. Tel: +81 666453838, Fax: +81 666466450, e-mail: spqv9ke9@view.ocn.ne.jp

Key Words: Eribulin, metastatic breast cancer, tumor microenvironment, immune response, chemotherapy.
( $p=0.012$ and $0.001 ; p=0.049$ and 0.018 , respectively). Conclusion: The efficacy of eribulin may be attributed to its biological effects on the immune system (reduction of PD-L1 and FOXP3 expression) through epithelial-mesenchymal transition suppression, and vascular remodeling and improvement of the tumor microenvironment.

Breast cancer is the second most common cancer worldwide, and the most common cancer in women. In 2012, there were an estimated 1.67 million new cases of breast cancer worldwide, and 522,000 deaths were attributed to breast cancer. Advanced breast cancer, particularly stage IV, is associated with poor outcomes and a recent study reported a median survival rate of 2.3 years and 10-year actuarial breast cancer-specific survival rates of $15.7 \%, 14.9 \%$, and $11.7 \%$, respectively, for women aged $\leq 40,41-50$, and 51-70 years at the time of diagnosis (1).

Initial treatment for breast cancer usually comprises surgical resection and radiotherapy, depending on the patient's condition. Adjuvant or neoadjuvant therapy with chemotherapy or molecular targeted therapies may also be valuable depending on the breast cancer's receptor status or other risk markers, such as nodal status, tumor grade, and lymphovascular invasion. In many countries, including Japan (2), treatment decisions are increasingly being led by the presence or absence of biomarkers and patient choice (3-5). Although many agents have been developed to target hormone receptors, these are unsuitable for treating triplenegative breast cancer, underscoring the need to target alternative molecular pathways. To understand why existing chemotherapies frequently show limited long-term efficacy, researchers are increasingly focusing on the tumor microenvironment in order to develop molecular-targeted drugs. It has become clear that cancer cells exploit molecular pathways to evade the immune system and chemotherapies.

Cells within the tumor microenvironment, including tumorinfiltrating lymphocytes and cancer cells, may be used to 
monitor immune responses and predict treatment responses $(6,7)$. In particular, it has been demonstrated that $\mathrm{T}$ cells and cancer cell phenotypes associated with a poor antitumor response display abnormal expression of programmed cell death protein (PD)-1, programmed death ligand-1 (PD-L1), PD-L2, and forkhead box P3 (FOXP3) (8).

The epithelial-mesenchymal transition (EMT) is a critical cellular transition by which cancer cells switch from an epithelial phenotype to a mesenchymal phenotype that supports their ability to migrate and invade other tissues (911). It was reported that inhibition of EMT could reduce this immunosuppression (12).

Eribulin mesylate (eribulin) is an analog of halichondrin B that causes microtubule depolymerization by inhibiting the growth rate of microtubules without affecting microtubule shortening (13). Additionally, several studies have demonstrated that eribulin is clinically-effective in patients with breast cancer $(14,15)$. In a pooled analysis of patients with metastatic breast cancer who had received at least one prior chemotherapy regimen, eribulin significantly extended overall survival (OS), and increased the progression-free survival (PFS) and clinical benefit rates compared with the control treatments (15). The survival benefit of eribulin was also apparent in patients with human epidermal growth factor receptor 2 (HER2)-negative or triple-negative breast cancer (15). Interestingly, in a preclinical study, eribulin demonstrated unique effects such as reversed EMT and induced mesenchymal-epithelial transition (MET) (16). This process may explain the clinical observation of prolonged OS in eribulin-treated patients.

It is important to analyze the effects of eribulin on microenvironments, including the immune microenvironment, and on the extent of EMT. To date, however, no studies have examined the effects of eribulin on the antitumor immune response in breast cancer. Therefore, the objectives of this study were to evaluate the changes in the tumor microenvironment, focusing on the antitumor immune response, in patients with advanced or metastatic breast cancer treated with eribulin.

\section{Materials and Methods}

Ethics. The research reported here conformed to the provisions of the Declaration of Helsinki (64th WMA General Assembly, Fortaleza, Brazil, October 2013). This study comprised a retrospective chart review. At the time of treatment, patients provided written informed consent for the use of their data in later research studies. The study protocol was approved by the Ethics Committee of Osaka City University (\#926).

Patients and treatments. We obtained and analyzed the electronic medical records of patients with metastatic breast cancer who underwent chemotherapy using eribulin from August 2011 to June 2013 at our institute. The cut-off was limited to June 2013 because few patients received eribulin after this date, and to ensure that there was sufficient follow-up. Patients received a chemotherapy regimen, in 21-day cycles, in which eribulin mesylate $\left(1.4 \mathrm{mg} / \mathrm{m}^{2}\right)$ was intravenously administered on days 1 and 8 , followed by a drug-free period until day 21 (17). This protocol was repeated until progressive disease was detected or a severe adverse event requiring the discontinuation of the scheduled chemotherapy was noted. Eribulin was administered in an outpatient setting.

Survival endpoints. The antitumor effect was evaluated according to the Response Evaluation Criteria in Solid Tumors version 1.1 (18). The overall response rate (ORR), clinical benefit rate (CBR), disease control rate (DCR), OS, time to treatment failure (TTF), and PFS were calculated as follows. The ORR was calculated as the sum of patients with complete response (CR) or partial response (PR). The CBR was calculated as $\mathrm{CR}+\mathrm{PR}+$ stable disease (SD) (for $>24$ weeks)/total number of patients. The DCR was calculated as $\mathrm{CR}+\mathrm{PR}+\mathrm{SD}$ (other)/total number of patients. The OS was evaluated daily and was calculated as the time from the start of treatment to the patient's death. The TTF was evaluated daily and was calculated as the time from the start of treatment to discontinuation of treatment for any reason, including disease aggravation, adverse events, or death. The PFS was evaluated daily and was calculated as the time from the start of treatment to either confirmation of progressive disease or death, whichever occurred first.

Tumor morphology and grading. Tumor morphology was assessed using tissue samples obtained by core needle biopsy at diagnosis or during breast cancer resection. Morphologic assessments included histological tissue type and nuclear grade, as evaluated by conventional hematoxylin and eosin (HE) staining. Breast cancer was classified into subtypes according to the immunohistochemical expression of estrogen receptor (ER), progesterone receptor $(\mathrm{PgR})$, HER2, and Ki67, yielding the following immunophenotypes:

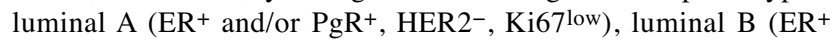
and/or PgR ${ }^{+}$, HER2- ${ }^{-}$Ki67 high), luminal HER2 (ER ${ }^{+}$and/or $\mathrm{PgR}^{+}$, HER2 $\left.{ }^{+}\right)$, HER2-enriched $\left(\mathrm{ER}^{-}, \mathrm{PgR}^{-}\right.$, and HER2 $\left.{ }^{+}\right)$, and triplenegative breast cancer $\left(\mathrm{ER}^{-}, \mathrm{PgR}^{-}\right.$, and HER2-) (19).

Immunohistochemical scoring was performed by two pathologists (M.O. and S.T.) specialized in mammary gland pathology who were blinded to the patient details to ensure the diagnosis was objective and reproducible. The cut-off values for ER and PgR positivity were set at $\geq 1 \%$ in accordance with previous studies (20). HER2 expression was scored using an accepted grading system $(0=$ no reactivity, or membranous reactivity in less than $10 \%$ of cells; $1+=$ faint/barely perceptible membranous reactivity in $\geq 10 \%$ of cells or reactivity in only part of the cell membrane; $2+=$ weak to moderate complete or basolateral membranous reactivity in $\geq 10 \%$ of tumor cells; or $3+=$ strong complete or basolateral membranous reactivity in $\geq 10 \%$ of tumor cells). HER2 expression was considered positive if the immunostaining score was $3+$ or $2+$ together with gene amplification via fluorescent in situ hybridization (FISH). For FISH analyses, each copy of the HER2 gene and its centromere 17 (CEP17) reference were counted. The interpretation followed the American Society of Clinical Oncology/College of American Pathologists guidelines for HER2 immunohistochemical classification of breast cancer, and was considered positive if the HER2/CEP17 ratio was $>2.0$ (21). A Ki67labeling index of $\geq 14 \%$ was classified as positive (19).

Immunohistochemistry. Immunohistochemistry was performed using tissue samples obtained by core needle biopsy at diagnosis or during 
breast cancer resection. Tumor specimens were fixed in $10 \%$ formaldehyde solution and embedded in paraffin, and 4- $\mu$ m-thick sections were mounted onto glass slides. Slides were deparaffinized in xylene and heated for $20 \min \left(105^{\circ} \mathrm{C}, 0.4 \mathrm{~kg} / \mathrm{m}^{2}\right)$ in an autoclave in Target Retrieval Solution (Dako, Carpinteria, CA, USA). Specimens were then incubated with $3 \%$ hydrogen peroxide in methanol for 15 min to block endogenous peroxidase activity, and then incubated in $10 \%$ normal goat or rabbit serum to block nonspecific reactions. Primary monoclonal antibodies directed against E-cadherin (clone NCH 38; Dako), PD-1 (clone NAT105; Abcam, Cambridge, UK), PD-L1 (clone 27A2; MBL, Nagoya, Japan), PDL2 (clone \#176611; R\&D Systems, Minneapolis, MN, USA), FOXP3 (clone 236A/E7; Abcam), and CD8 (clone C8/144B; Dako) were used. Tissue sections were incubated with each antibody for $70 \mathrm{~min}$ at room temperature or overnight at $4^{\circ} \mathrm{C}$, and then incubated with horseradish peroxidase-conjugated anti-rabbit or anti-mouse Ig secondary antibodies (HISTOFINE [PO] ${ }^{\mathrm{TM}} \mathrm{Kit}$; Nichirei, Tokyo, Japan). The slides were subsequently treated with streptavidinperoxidase reagent and incubated in phosphate-buffered salinediaminobenzidine and $1 \%$ hydrogen peroxide $(\mathrm{v} / \mathrm{v})$, followed by counterstaining with Mayer's hematoxylin. Positive and negative controls for each marker were used according to the manufacturer's data sheets for each antibody.

PD-1 is a cell surface receptor that plays an important role in negative regulation in the immune system. Its ligands, PD-L1 and PD-L2 are also cell surface proteins and can bind to PD-1. FOXP3, a marker of regulatory $\mathrm{T}$ cells that has a suppressive function for effector T cells, such as $\mathrm{CD}^{+}$killer $\mathrm{T}$ cells, was evaluated. To evaluate PD-1, FOXP3, and CD8 expression, the number of tumorinfiltrating lymphocytes in the stroma surrounding cancer cells labelled with anti-PD-1, anti-FOXP3, or anti-CD8 antibodies was counted at a magnification of $200 \times$ in each of three fields of view (FOVs) selected in darkly stained areas. In accordance with previous studies $(22,23)$, the median value of the mean of all three FOVs was determined, and that number was set as a cut-off value To evaluate PD-L1, PD-L2, and E-cadherin, three FOVs in darkly stained areas were selected, and the percentage of cancer cells stained with the corresponding antibody in each FOV was determined at a magnification of $400 \times$. In accordance with a previous study (24), the median value of the mean of all three FOVs was determined; high expression was defined as expression in $\geq 10 \%$ of cells for PD-L1, PD-L2, and E-cadherin. Representative immunohistochemical slides are shown in Figure 1.

It was previously reported that eribulin regulated EMT (16), and we reported that E-cadherin expression became positive in tissues from locally advanced or metastatic breast cancer patients with objective clinical response to eribulin treatment (25). Therefore, the relationship between EMT and immune regulation by eribulin was analyzed.

Statistical analyses. Statistical analyses were performed using SPSS $^{\circledR}$ version 19.0 statistical software (IBM, Armonk, NY, USA). Categorical data are represented as numbers and percentages, and continuous data are represented as medians and range. The association between treatment efficacy and clinicopathological variables was analyzed using Fisher's exact test. Survival rates were evaluated using Kaplan-Meier plots and log-rank tests. In all analyses, $p<0.05$ was considered statistically significant. The cutoff values for the biomarkers included in this study were chosen before conducting the statistical analysis.

\section{Results}

Patients. Overall, 52 patients were identified from their medical records, and the median follow-up time was 431 days (range $=50-650$ days). The mean age of patients was 63.5 years (Table I). One-quarter of the patients had locally advanced cancer and $75 \%$ had visceral metastases. Overall, $51.9 \%, 38.5 \%, 9.6 \%$, and $50.0 \%$ of patients were $\mathrm{ER}^{+}, \mathrm{PgR}^{+}$, $\mathrm{HER}^{+}{ }^{+}$, or $\mathrm{Ki}_{6} 7^{+}$, respectively; $42.3 \%$ of patients had triplenegative breast cancer. In 11 patients, tissue samples were obtained at diagnosis and during surgical resection after being treated with eribulin (surgical cohort). Their characteristics were consistent with those of the overall cohort.

Survival and cancer outcomes in the overall cohort. Table II shows the survival and cancer outcomes of the total cohort and of the 11 patients in the surgical cohort. In the overall cohort, the median OS, PFS, and TTF were 431 days (range $=50-650$ days), 325 days (range $=40-650$ days), and 155 days (range $=49-650$ days), respectively. CR was achieved in 1 patient $(1.9 \%)$, PR in 17 patients $(32.7 \%)$, and $\mathrm{SD}$ in 9 patients $(17.3 \%)$ in the overall cohort. Five patients had SD for $>24$ weeks and 4 patients had SD for $\leq 24$ weeks. The ORR, CBR, and DCR were $34.6 \%$ (18/52), $44.2 \%$ $(23 / 52)$, and $51.9 \%(27 / 52)$, respectively, in the overall cohort. These rates tended to be lower in triple-negative breast cancer subtypes than in other cancer subtypes.

Immunohistochemistry. Tissue samples were obtained at diagnosis and after surgical resection and treatment with eribulin in 11 patients, but one patient had pathological CR and tissue samples were unavailable for immunohistochemistry. Therefore, immunohistochemical data were available for 10 patients: 5 with PR and 5 non-responders. In general, eribulin was administered within 1 month of diagnosis, and the resections were performed within 1 month of determining the effect of eribulin. Using the immunohistochemical data for these 10 patients, the expression rate of PD-1, PD-L1, PD-L2, CD8, and FOXP3 in each tissue specimen before and after eribulin treatment was plotted (Figure 2). The expression levels of PD-1, PDL1, and FOXP3 decreased in all 5 responders to eribulin, increased CD8 expression was observed in $4 / 5$ responders, and expression of PD-L2 was decreased in 4/5 responders. The positive or negative conversions in the expression levels of these markers tended to occur in opposite directions in non-responders. The response to eribulin was significantly associated with PD-L1 and FOXP3 negative conversion ( $p=0.024$ and 0.004 , respectively; Table III).

Regarding the analysis of the relationship between EMT and immune regulation by eribulin, the change in E-cadherin expression (positive or negative) was also correlated with the 
Table I. Patient characteristics.

\begin{tabular}{|c|c|c|c|}
\hline Variable & \multicolumn{2}{|c|}{$\begin{array}{l}\text { Total cohort } \\
\quad(\mathrm{n}=52)\end{array}$} & $\begin{array}{l}\text { Surgical cohort } \\
\qquad(\mathrm{n}=11)\end{array}$ \\
\hline Age (years) & \multicolumn{2}{|c|}{$63.5 \pm 12.7$} & $58.0 \pm 13.7$ \\
\hline \multicolumn{4}{|l|}{ Progression } \\
\hline Locally advanced & \multicolumn{2}{|c|}{$13(25.0 \%)$} & $7(63.6 \%)$ \\
\hline Visceral metastases & \multicolumn{2}{|c|}{$39(75.0 \%)$} & $4(36.4 \%)$ \\
\hline \multicolumn{4}{|l|}{ Site of metastases } \\
\hline Lung & \multicolumn{2}{|c|}{$19(36.5 \%)$} & $3(27.3 \%)$ \\
\hline Bone & \multicolumn{2}{|c|}{$19(36.5 \%)$} & $3(27.3 \%)$ \\
\hline Liver & \multicolumn{2}{|c|}{$18(34.6 \%)$} & $1(9.1 \%)$ \\
\hline \multicolumn{4}{|l|}{ Life-threatening condition } \\
\hline Life-threatening & \multicolumn{2}{|c|}{$14(26.9 \%)$} & $0(0.0 \%)$ \\
\hline \multirow[t]{2}{*}{ Non-life-threatening } & \multicolumn{2}{|c|}{$38(73.1 \%)$} & $11(100.0 \%)$ \\
\hline & \multicolumn{2}{|r|}{$\begin{array}{l}\text { Preoperative } \\
\quad(\mathrm{n}=11)\end{array}$} & $\begin{array}{l}\text { e Postoperative } \\
\qquad(\mathrm{n}=10)^{\mathrm{a}}\end{array}$ \\
\hline \multicolumn{4}{|l|}{ Nuclear grade } \\
\hline 1 & $13(25.0 \%)$ & $2(18.2 \%)$ & $4(40.0 \%)$ \\
\hline 2 & $20(38.5 \%)$ & $2(18.2 \%)$ & $4(40.0 \%)$ \\
\hline 3 & $19(36.5 \%)$ & $7(63.6 \%)$ & $2(20.0 \%)$ \\
\hline Estrogen receptor-positive & $27(51.9 \%)$ & $4(36.4 \%)$ & $3(30.0 \%)$ \\
\hline Progesterone receptor-positive & $20(38.5 \%)$ & $2(18.2 \%)$ & $3(30.0 \%)$ \\
\hline HER2-positive & $5(9.6 \%)$ & $0(0.0 \%)$ & $0(0.0 \%)$ \\
\hline Ki67-positive & $26(50.0 \%)$ & $8(72.7 \%)$ & $5(50.0 \%)$ \\
\hline \multicolumn{4}{|l|}{ Intrinsic subtype } \\
\hline Luminal A & $12(23.1 \%)$ & $2(18.2 \%)$ & $1(10.0 \%)$ \\
\hline Luminal B & $13(15.0 \%)$ & $2(18.2 \%)$ & $2(20.0 \%)$ \\
\hline Luminal HER2 & $2(3.8 \%)$ & $0(0.0 \%)$ & $0(0.0 \%)$ \\
\hline HER2 enriched & $3(5.8 \%)$ & $0(0.0 \%)$ & $0(0.0 \%)$ \\
\hline Triple negative & $22(42.3 \%)$ & $7(63.6 \%)$ & $7(70.0 \%)$ \\
\hline
\end{tabular}

ammunohistochemistry was unavailable in 1 patient with pathological complete response. Values are expressed as the mean \pm standard deviation or number $(\%)$ of patients. HER2: Human epidermal growth factor receptor 2 .

changes in PD-L1 and FOXP3 $(p=0.024$ and 0.004, respectively; Table IV).

Kaplan-Meier analysis (Figure 3) with log-rank tests revealed that PFS and TTF were significantly longer in patients with PD-L1 negative conversion ( $p=0.012$ and 0.001 , respectively) compared with other patients. In the case of FOXP3 negative conversion, PFS and TTF were also significantly longer in patients with PD-L1 negative conversion $(p=0.049$ and 0.018$)$.

\section{Discussion}

In this retrospective study, we assessed the treatment and survival outcomes after eribulin treatment in a cohort of 52 Japanese patients with metastatic breast cancer. The effects of eribulin on the tumor microenvironment and expression of immune-related biomarkers was also examined in 10 patients in whom immunochemistry was performed at diagnosis and after treatment with eribulin. The median OS, PFS, and TTF were 431, 325, and 155 in the overall cohort, and the ORR, CBR, and DCR were $34.6 \%, 44.2 \%$, and $51.9 \%$, respectively. In a pooled analysis of patients who had received at least one prior chemotherapy, the median OS and PFS for eribulin were 15.0 months and 3.9 months, respectively, while the CBR was $30 \%$ (15). Therefore, our results in this cohort of Japanese patients were generally similar to those in two European phase 3 trials (15).

Changes in the tumor microenvironment were also examined in 10 patients in whom tissue samples were available before and after treatment with eribulin. Although we observed some variability in the microenvironmental responses, the results suggest that responders to eribulin were more likely to show decreases in PD-L1 and FOXP3 expression compared with non-responders. The decrease of the inhibitory molecules in the responders and the increase in CD8, which may be caused by an influx on $\mathrm{CD}^{+} \mathrm{T}$ cells, suggest that eribulin promotes an antitumor immune response, and that these changes were associated with longer PFS and TTF than in non-responders.

It has been proposed that eribulin renders residual tumors less aggressive and less likely to metastasize by triggering a shift from mesenchymal to epithelial phenotypes by reversing EMT to MET (16). In addition, we have previously reported that all eribulin responders demonstrated positive conversion to E-cadherin expression, suggesting that eribulin inhibited EMT (25). A variety of factors in the tumor microenvironment can promote EMT. In particular, inflammation, hypoxia, and stem cells in the tumor microenvironment are inextricably linked to the EMT through complex pathways that are only now becoming fully understood (10). One key mediator may be hypoxia inducible factor- $1 \alpha$ (HIF-1 $\alpha)$, which is induced by hypoxia and growth factors. HIF-1 $\alpha$ was reported to mediate EMT and cancer cell metastasis by upregulating Snail and TWIST1 expression, and hence promoting the morphological change of epithelial cells to a mesenchymal phenotype (26). Interestingly, eribulin was reported to improve tumor perfusion in human breast cancer tumor models, an effect driven by vascular remodeling associated with increased numbers of smaller functional microvessels. The increase in tumor perfusion alleviates hypoxic stress (and hence HIF-1 $\alpha$ ) associated with the abnormal tumor microenvironment (27).

It was also reported that eribulin induced reoxygenation by vascular remodeling in advanced breast cancer patients (28). In our previously study, CA9 expression, an indicator of hypoxia, was significantly decreased in eribulin responders suggesting that eribulin improved the hypoxic condition (25). The researchers mentioned that TGF- $\beta$, which is typically associated with hypoxic conditions, was decreased in the eribulin-treated group. TGF- $\beta$ plays crucial roles in EMT and in immune regulation, including the induction of regulatory $\mathrm{T}$ cells and the suppression of 


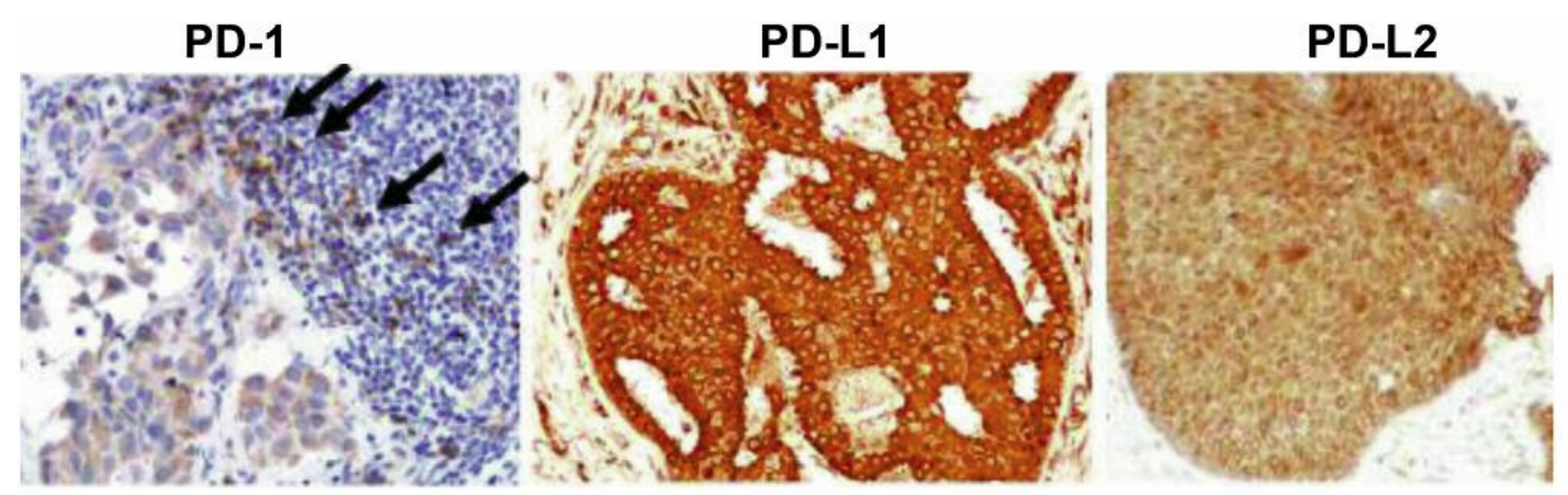

\section{CD8}

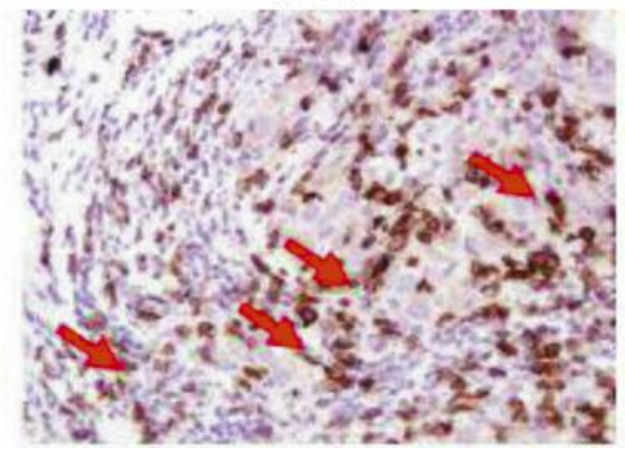

FOXP3

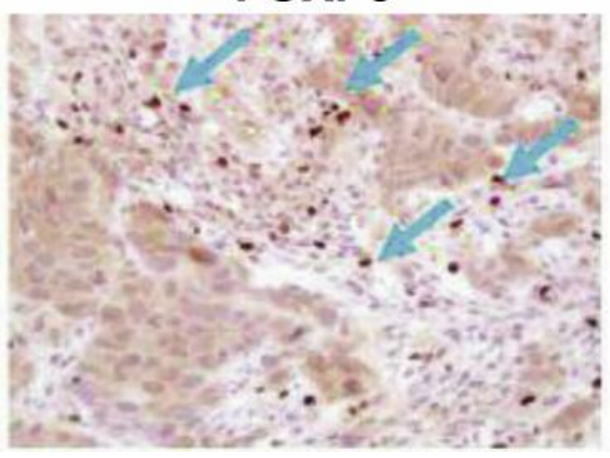

Figure 1. Representative immunohistochemical staining. Black arrows point to PD-1+ lymphocytes, red arrows point to CD8+ lymphocytes, and blue arrows point to FOXP3+ lymphocytes. The PD-L1- and PD-L2-positive cells show cytoplasmic staining. PD-1: Programmed death 1; PD-L: programmed death ligand; FOXP3: forkhead box P3.
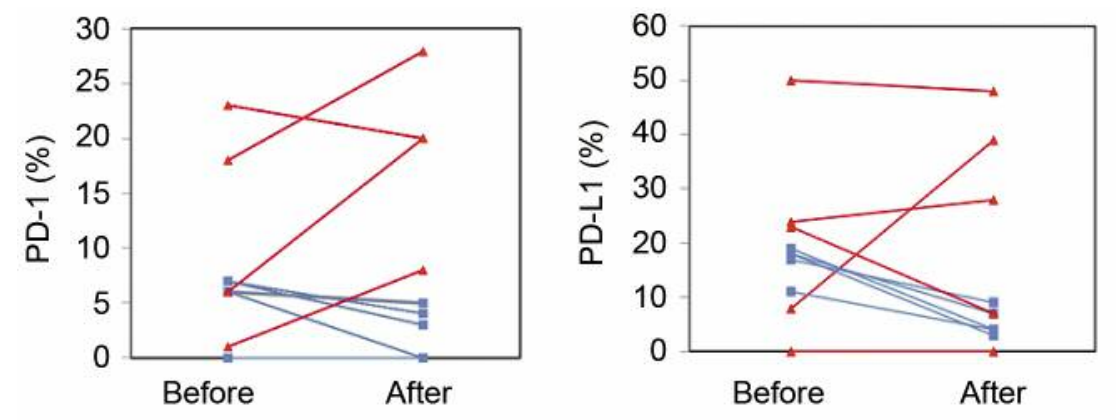
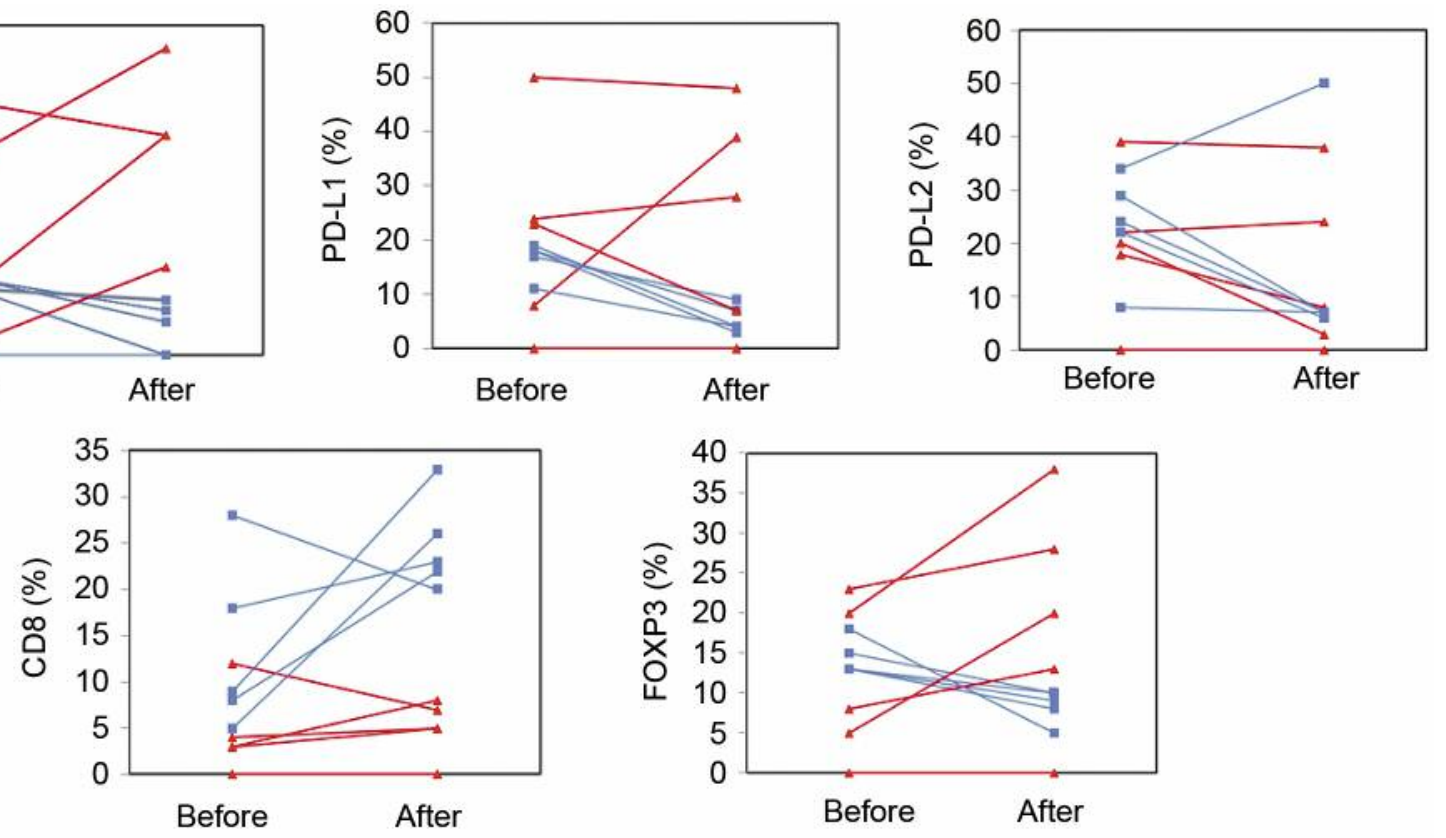

Figure 2. Immunohistochemical analysis of immune biomarkers in metastatic breast cancer samples before and after treatment with eribulin (evaluable patients, $n=10$ ). \% refers to the percentage of positive cells. The blue squares/lines show the results for responders and the red triangles/lines show the results for non-responders. PD-1: Programmed death 1; PD-L: programmed death ligand; FOXP3: forkhead box P3. 
Table II. Survival outcomes.

\begin{tabular}{|c|c|c|c|c|c|c|}
\hline & \multirow{2}{*}{$\begin{array}{l}\text { Total cohort } \\
\quad(\mathrm{n}=52)\end{array}$} & \multicolumn{2}{|c|}{ Intrinsic subtype $(n=52)$} & \multirow{2}{*}{$\begin{array}{l}\text { Surgical cohort } \\
\qquad(\mathrm{n}=11)\end{array}$} & \multicolumn{2}{|c|}{ Intrinsic subtype $(\mathrm{n}=11)$} \\
\hline & & $\begin{array}{c}\text { Non-triple } \\
\text { negative } \\
(n=30,57.7 \%)\end{array}$ & $\begin{array}{c}\text { Triple } \\
\text { negative } \\
(\mathrm{n}=22,42.3 \%)\end{array}$ & & $\begin{array}{c}\text { Non-triple } \\
\text { negative } \\
(n=4,36.4 \%)\end{array}$ & $\begin{array}{c}\text { Triple } \\
\text { negative } \\
(\mathrm{n}=7,63.4 \%)\end{array}$ \\
\hline ORR & $18(34.6 \%)$ & $12(40.0 \%)$ & $6(27.3 \%)$ & $6(54.5 \%)$ & $3(75.0 \%)$ & $3(42.9 \%)$ \\
\hline CBR & $23(44.2 \%)$ & $15(50.0 \%)$ & $8(36.4 \%)$ & $7(63.6 \%)$ & $3(75.0 \%)$ & $4(57.7 \%)$ \\
\hline DCR & $27(51.9 \%)$ & $18(60.0 \%)$ & $9(40.9 \%)$ & $8(72.7 \%)$ & $3(75.0 \%)$ & $5(71.4 \%)$ \\
\hline $\mathrm{CR}$ & $1(1.9 \%)$ & $1(3.3 \%)$ & $0(0.0 \%)$ & $1(9.1 \%)$ & $1(25.0 \%)$ & $0(0.0 \%)$ \\
\hline PR & $17(32.7 \%)$ & $11(36.7 \%)$ & $6(27.3 \%)$ & $5(45.4 \%)$ & $2(50.0 \%)$ & $3(42.8 \%)$ \\
\hline SD & $9(17.3 \%)$ & $3(10.0 \%)$ & $1(4.5 \%)$ & $2(18.2 \%)$ & $0(0.0 \%)$ & $1(14.3 \%)$ \\
\hline PD & $20(38.5 \%)$ & $7(23.3 \%)$ & $13(59.1 \%)$ & $3(27.3 \%)$ & $1(25.0 \%)$ & $2(28.6 \%)$ \\
\hline $\mathrm{NE}$ & $5(9.6 \%)$ & $5(16.7 \%)$ & $0(0.0 \%)$ & $0(0.0 \%)$ & $0(0.0 \%)$ & $0(0.0 \%)$ \\
\hline
\end{tabular}

Values are expressed as the number (\%) of patients. ORR: Objective response rate; CBR: clinical benefit rate; DCR: disease control rate; CR: complete response; PR: partial response; SD: stable disease; PD: progressive disease; NE: not evaluable.

Table III. Correlation between the response to eribulin and immune biomarker expression

\begin{tabular}{lccc}
\hline & $\begin{array}{c}\text { Responders } \\
(\mathrm{n}=5)\end{array}$ & $\begin{array}{c}\text { Non-responders } \\
(\mathrm{n}=5)\end{array}$ & $p$-Value \\
\hline $\begin{array}{l}\text { Hormone receptor and } \\
\text { HER2 status }\end{array}$ & & & \\
$\quad$ Triple negative & $4(80 \%)$ & $3(60 \%)$ & 0.500 \\
$\quad$ Non-triple negative & $1(20 \%)$ & $2(40 \%)$ & \\
PD-1 & & & 0.103 \\
$\quad$ Negative conversion & $4(80 \%)$ & $1(20 \%)$ & \\
Other & $1(20 \%)$ & $4(80 \%)$ & \\
PD-L1 & $5(100 \%)$ & $1(20 \%)$ & 0.024 \\
$\quad$ Negative conversion & $0(0 \%)$ & $4(80 \%)$ & \\
Other & & & 0.500 \\
PD-L2 & $3(60 \%)$ & $2(40 \%)$ & \\
$\quad$ Negative conversion & $2(40 \%)$ & $3(60 \%)$ & 0.083 \\
Other & & & \\
CD8 & $3(60 \%)$ & $0(0 \%)$ & \\
Positive conversion & $2(40 \%)$ & $5(100 \%)$ & \\
$\quad$ Other & & & 0.004 \\
FOXP3 & $5(100 \%)$ & $0(0 \%)$ & \\
Negative conversion & $0(0 \%)$ & $5(100 \%)$ & \\
Other &
\end{tabular}

Values are expressed as the number (\%) of patients. HER2: Human epidermal growth factor receptor 2; PD-1: programmed death 1; PD-L: programmed death ligand; FOXP3: forkhead box P3.

effector T cells. It was found that hypoxia induced EMT (29, 30) and increased the expression of PD-L1 via the HIF-1 transcription factor on myeloid-derived suppressor cells (31). Recently, researchers demonstrated that PD-L1 is upregulated in EMT-activated human breast cancer cells by a mechanism involving ZEB-1 and miR-200 (32).
Table IV. Correlation between E-cadherin expression and changes in immune biomarkers.

\begin{tabular}{lccc}
\hline & $\begin{array}{c}\text { E-cadherin } \\
\text { positive }(\mathrm{n}=5)\end{array}$ & $\begin{array}{c}\text { E-cadherin } \\
\text { negative }(\mathrm{n}=5)\end{array}$ & $p$-Value \\
\hline PD-1 & & & 0.103 \\
$\quad$ Negative conversion & $4(80 \%)$ & $1(20 \%)$ & \\
$\quad$ Other & $1(20 \%)$ & $4(80 \%)$ & 0.024 \\
PD-L1 & & & \\
$\quad$ Negative conversion & $5(100 \%)$ & $1(20 \%)$ & \\
$\quad$ Other & $0(0 \%)$ & $4(80 \%)$ & 0.004 \\
FOXP3 & $5(100 \%)$ & $0(0 \%)$ & \\
$\quad$ Negative conversion & $0(0 \%)$ & $5(100 \%)$ & \\
Other & & & \\
\hline
\end{tabular}

Values are expressed as the number (\%) of patients. PD-1: Programmed death 1; PD-L1: programmed death ligand 1; FOXP3: forkhead box P3.

Our results suggest that eribulin may also inhibit an immune evasion mechanism involving immune checkpoints and improve the cancer immune microenvironment in breast cancer (Figure 4). Taken together, it is possible that eribulin regulates EMT and immune responses through vascular remodeling. Kudo-Saito et al. reported that in melanoma cells with typical EMT features, upregulation of Snailinduced regulatory $\mathrm{T}$ cells and impaired dendritic cells in vitro and in vivo, partly through thrombospondin-1 production (12). Meanwhile, Snail knockdown reduced the effects of Snail in terms of tumor metastasis and immunosuppression, and was followed by tumor inhibition along with local infiltration of antitumor effector cells in tumor tissues and systemic induction of tumor-specific $\mathrm{CD} 8^{+}$ T-cell responses in vivo (12). In this manner, EMT also 
A

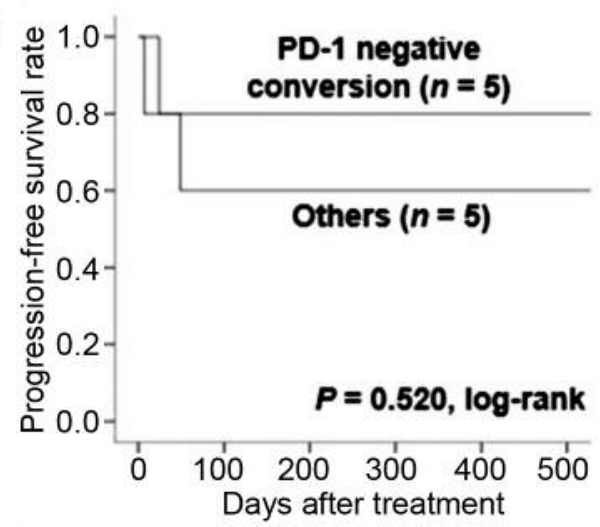

C

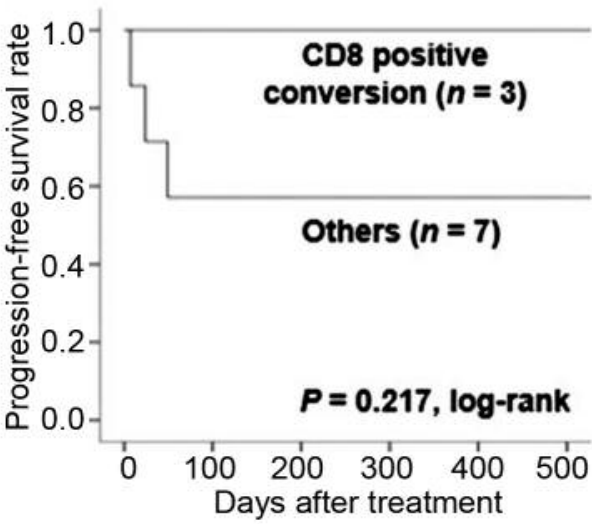

E

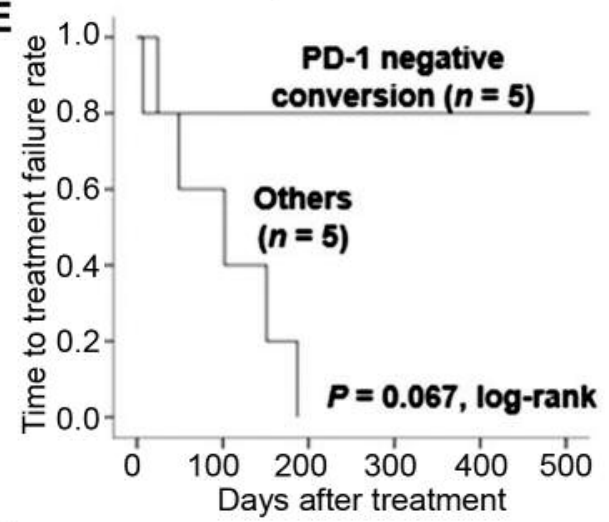

G

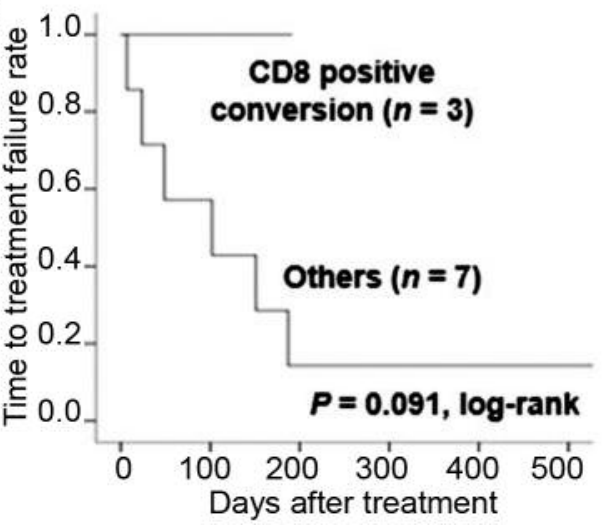

B

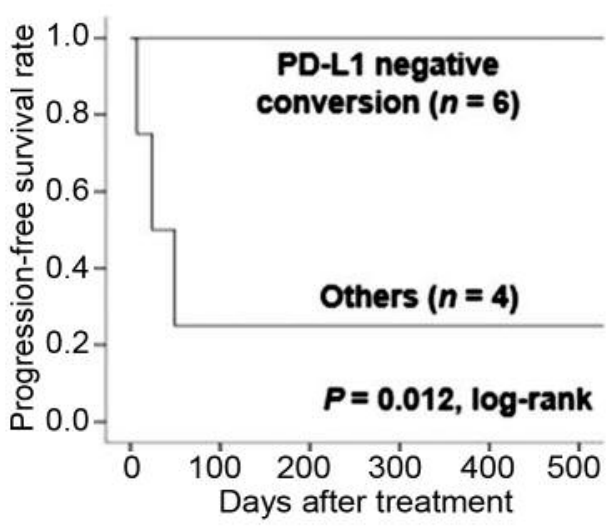

D

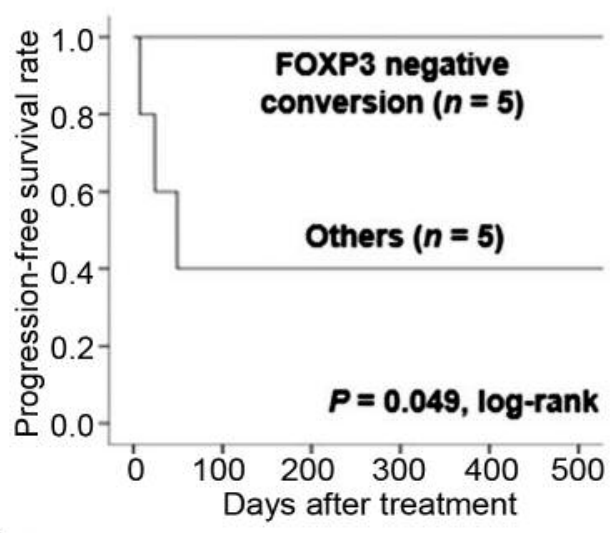

F
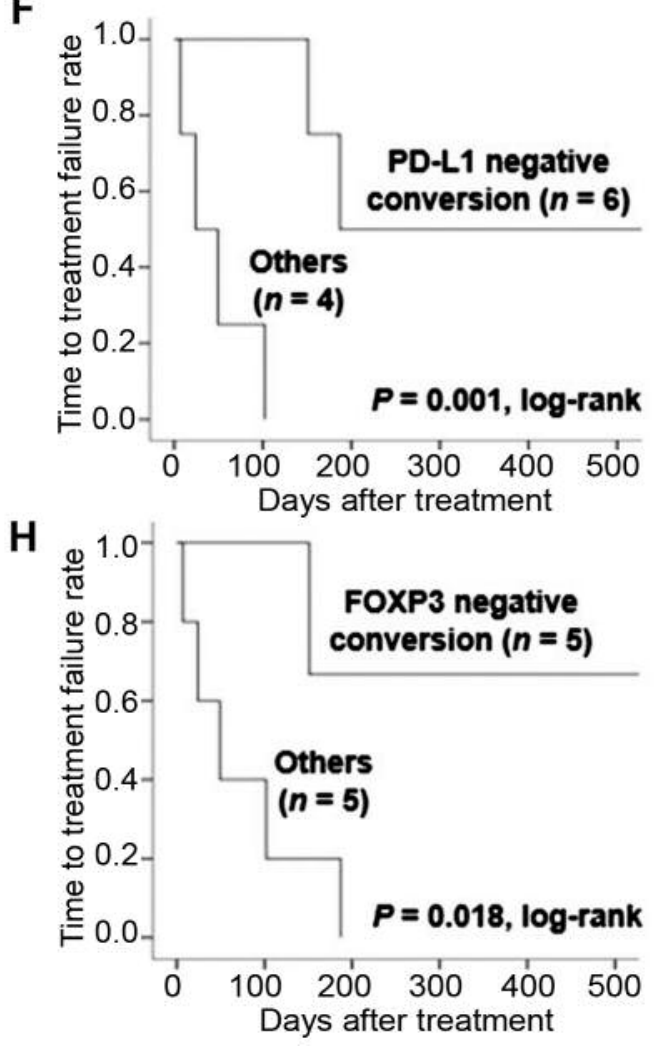

Figure 3. Progression-free survival (A-D) and time to treatment failure $(E-H)$ in the surgical cohort according to changes in PD-1, PD-L1, CD8, and FOXP3 (n=10). PD-1: Programmed death 1; PD-L: programmed death ligand; FOXP3: forkhead box P3. 


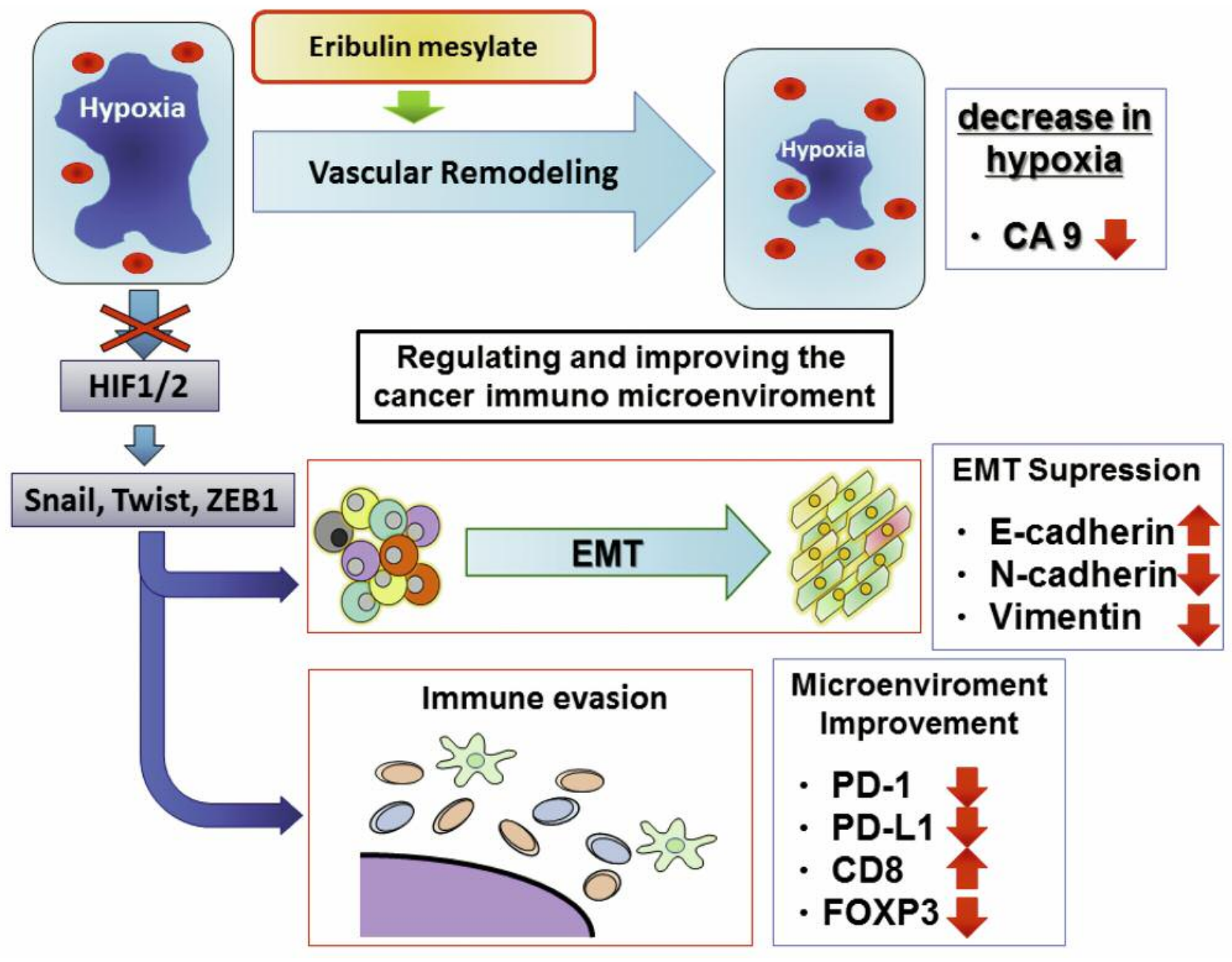

Figure 4. Proposed molecular mechanism of eribulin in metastatic breast cancer. EMT: Epithelial-mesenchymal transition; HIF: hypoxia-inducible factor; PD-1: programmed death 1; PD-L: programmed death ligand; FOXP3: forkhead box P3.

regulated immune functions in tumor tissues. We have previously reported that the number of tumor-infiltrating lymphocytes is a predictive marker for eribulin-responders (33). Our updated results indicate that eribulin accelerated the anti-tumor immune response and also showed efficacy in patients with metastatic breast cancer.

Interestingly, some non-responders showed favorable responses to eribulin in that the changes in protein expression were consistent with those in responders. The reason why these patients did not experience a tumor response is unclear and warrants clarification. It is feasible that the beneficial effects of eribulin on the tumor microenvironment were insufficient to counteract other cellular mechanisms involved in cancer progression. If so, some patients may benefit from being administered eribulin in combination with drugs targeting independent or complementary pathways. Alternatively, the disease may have been too advanced in some non-responders to observe a clear benefit from eribulin.

It is important to acknowledge that immunohistochemistry was performed using tissue samples before and after treatment with eribulin in just 10 of 52 patients. Therefore, the results might not fully reflect the changes in expression in the wider population of patients with advanced or metastatic breast cancer treated with eribulin.

The results of this study and those of prior studies, lead to the conclusion that by inhibiting the EMT, eribulin may enhance the antitumor immune response by improving the cancer immune microenvironment. In patients with locally advanced or metastatic breast cancer, the efficacy of eribulin might be attributed to the biological effects of eribulin on the immune system on the basis of EMT and/or vascular remodeling. 


\section{Conflicts of Interest}

The Authors have no conflicts of interest to disclose.

\section{Acknowledgements}

The Authors would like to thank Sayaka Tanaka from the Department of Diagnostic Pathology, Osaka City University Graduate School of Medicine, for providing assistance with immunohistochemical scoring. The Authors also thank Yayoi Matsukiyo and Tomomi Okawa (Department of Surgical Oncology, Osaka City University Graduate School of Medicine) for their helpful advice regarding data management. This study was funded by grants from the Japan Society for the Promotion of Science (KAKENHI, Nos. 25461992, 26461957, and 17K10559) to Shinichiro Kashiwagi. The Authors thank Nicholas D. Smith (Edanz Medical Writing) for medical writing support, which was funded by Eisai Co., Ltd.

\section{References}

1 Eng LG, Dawood S, Sopik V, Haaland B, Tan PS, Bhoo-Pathy $\mathrm{N}$, Warner E, Iqbal J, Narod SA and Dent R: Ten-year survival in women with primary stage IV breast cancer. Breast Cancer Res Treat 160: 145-152, 2016.

2 Masuda S: Pathological examination of breast cancer biomarkers: current status in Japan. Breast Cancer 23: 546-551, 2016.

3 Henry NL, Somerfield MR, Abramson VG, Allison KH, Anders CK, Chingos DT, Hurria A, Openshaw TH and Krop IE: Role of Patient and Disease Factors in Adjuvant Systemic Therapy Decision Making for Early-Stage, Operable Breast Cancer: American Society of Clinical Oncology Endorsement of Cancer Care Ontario Guideline Recommendations. J Clin Oncol 34: 2303-2311, 2016.

4 Rugo HS, Rumble RB, Macrae E, Barton DL, Connolly HK, Dickler MN, Fallowfield L, Fowble B, Ingle JN, Jahanzeb M, Johnston SR, Korde LA, Khatcheressian JL, Mehta RS, Muss HB and Burstein HJ: Endocrine Therapy for Hormone ReceptorPositive Metastatic Breast Cancer: American Society of Clinical Oncology Guideline. J Clin Oncol 34: 3069-3103, 2016.

5 Van Poznak C, Somerfield MR, Bast RC, Cristofanilli M, Goetz MP, Gonzalez-Angulo AM, Hicks DG, Hill EG, Liu MC, Lucas W, Mayer IA, Mennel RG, Symmans WF, Hayes DF and Harris LN: Use of Biomarkers to Guide Decisions on Systemic Therapy for Women With Metastatic Breast Cancer: American Society of Clinical Oncology Clinical Practice Guideline. J Clin Oncol 33: 2695-2704, 2015.

6 Salgado R, Denkert C, Demaria S, Sirtaine N, Klauschen F, Pruneri G, Wienert S, Van den Eynden G, Baehner FL, PenaultLlorca F, Perez EA, Thompson EA, Symmans WF, Richardson AL, Brock J, Criscitiello C, Bailey H, Ignatiadis M, Floris G, Sparano J, Kos Z, Nielsen T, Rimm DL, Allison KH, Reis-Filho JS, Loibl S, Sotiriou C, Viale G, Badve S, Adams S, Willard-Gallo $\mathrm{K}$, Loi $\mathrm{S}$ and International TWG: The evaluation of tumorinfiltrating lymphocytes (TILs) in breast cancer: recommendations by an International TILs Working Group 2014. Ann Oncol 26: 259-271, 2015.

7 Savas P, Salgado R, Denkert C, Sotiriou C, Darcy PK, Smyth $\mathrm{MJ}$ and Loi S: Clinical relevance of host immunity in breast cancer: from TILs to the clinic. Nat Rev Clin Oncol 13: 228$241,2016$.

8 Asano Y, Kashiwagi S, Goto W, Kurata K, Noda S, Takashima T, Onoda N, Tanaka S, Ohsawa M and Hirakawa K: Tumourinfiltrating $\mathrm{CD} 8$ to FOXP3 lymphocyte ratio in predicting treatment responses to neoadjuvant chemotherapy of aggressive breast cancer. Br J Surg 103: 845-854, 2016.

9 Floor S, van Staveren WC, Larsimont D, Dumont JE and Maenhaut C: Cancer cells in epithelial-to-mesenchymal transition and tumor-propagating-cancer stem cells: distinct, overlapping or same populations. Oncogene 30: 4609-4621, 2011.

10 Jing Y, Han Z, Zhang S, Liu Y and Wei L: EpithelialMesenchymal Transition in tumor microenvironment. Cell Biosci 1: 29, 2011.

11 Thiery JP, Acloque H, Huang RY and Nieto MA: Epithelialmesenchymal transitions in development and disease. Cell 139: 871-890, 2009.

12 Kudo-Saito C, Shirako H, Takeuchi T and Kawakami Y: Cancer metastasis is accelerated through immunosuppression during Snail-induced EMT of cancer cells. Cancer Cell 15: 195-206, 2009.

13 Dybdal-Hargreaves NF, Risinger AL and Mooberry SL: Eribulin mesylate: mechanism of action of a unique microtubule-targeting agent. Clin Cancer Res 21: 2445-2452, 2015.

14 Dell'Ova M, De Maio E, Guiu S, Roca L, Dalenc F, Durigova A, Pinguet F, Bekhtari K, Jacot W and Pouderoux S: Tumour biology, metastatic sites and taxanes sensitivity as determinants of eribulin mesylate efficacy in breast cancer: results from the ERIBEX retrospective, international, multicenter study. BMC Cancer 15: 659, 2015.

15 Pivot X, Marme F, Koenigsberg R, Guo M, Berrak E and Wolfer A: Pooled analyses of eribulin in metastatic breast cancer patients with at least one prior chemotherapy. Ann Oncol 27: 1525-1531, 2016.

16 Yoshida T, Ozawa Y, Kimura T, Sato Y, Kuznetsov G, Xu S, Uesugi M, Agoulnik S, Taylor N, Funahashi Y and Matsui J: Eribulin mesilate suppresses experimental metastasis of breast cancer cells by reversing phenotype from epithelialmesenchymal transition (EMT) to mesenchymal-epithelial transition (MET) states. Br J Cancer 110: 1497-1505, 2014.

17 Cortes J, O'Shaughnessy J, Loesch D, Blum JL, Vahdat LT, Petrakova K, Chollet P, Manikas A, Dieras V, Delozier T, Vladimirov V, Cardoso F, Koh H, Bougnoux P, Dutcus CE, Seegobin S, Mir D, Meneses N, Wanders J, Twelves C and investigators: Eribulin monotherapy versus treatment of physician's choice in patients with metastatic breast cancer (EMBRACE): a phase 3 open-label randomised study. Lancet 377: 914-923, 2011.

18 Eisenhauer EA, Therasse P, Bogaerts J, Schwartz LH, Sargent D, Ford R, Dancey J, Arbuck S, Gwyther S, Mooney M, Rubinstein L, Shankar L, Dodd L, Kaplan R, Lacombe D and Verweij J: New response evaluation criteria in solid tumours: revised RECIST guideline (version 1.1). Eur J Cancer 45: 228247, 2009.

19 Goldhirsch A, Wood WC, Coates AS, Gelber RD, Thurlimann B, Senn HJ and Panel M: Strategies for subtypes - dealing with the diversity of breast cancer: highlights of the St. Gallen International Expert Consensus on the Primary Therapy of Early Breast Cancer 2011. Ann Oncol 22: 1736-1747, 2011. 
20 Umemura S, Kurosumi M, Moriya T, Oyama T, Arihiro K, Yamashita H, Umekita Y, Komoike Y, Shimizu C, Fukushima H, Kajiwara $\mathrm{H}$ and Akiyama $\mathrm{F}$ : Immunohistochemical evaluation for hormone receptors in breast cancer: a practically useful evaluation system and handling protocol. Breast Cancer 13: 232235, 2006

21 Wolff AC, Hammond ME, Hicks DG, Dowsett M, McShane LM, Allison KH, Allred DC, Bartlett JM, Bilous M, Fitzgibbons P, Hanna W, Jenkins RB, Mangu PB, Paik S, Perez EA, Press MF, Spears PA, Vance GH, Viale G, Hayes DF, American Society of Clinical $O$ and College of American $P$ : Recommendations for human epidermal growth factor receptor 2 testing in breast cancer: American Society of Clinical Oncology/College of American Pathologists clinical practice guideline update. J Clin Oncol 31: 3997-4013, 2013.

22 Muenst S, Schaerli AR, Gao F, Daster S, Trella E, Droeser RA, Muraro MG, Zajac P, Zanetti R, Gillanders WE, Weber WP and Soysal SD: Expression of programmed death ligand 1 (PD-L1) is associated with poor prognosis in human breast cancer. Breast Cancer Res Treat 146: 15-24, 2014.

23 Miyashita M, Sasano H, Tamaki K, Hirakawa H, Takahashi Y, Nakagawa S, Watanabe G, Tada H, Suzuki A, Ohuchi N and Ishida T: Prognostic significance of tumor-infiltrating $\mathrm{CD}^{+}$and FOXP3+ lymphocytes in residual tumors and alterations in these parameters after neoadjuvant chemotherapy in triple-negative breast cancer: a retrospective multicenter study. Breast Cancer Res 17: 124, 2015.

24 Kashiwagi S, Yashiro M, Takashima T, Nomura S, Noda S, Kawajiri $\mathrm{H}$, Ishikawa $\mathrm{T}$, Wakasa $\mathrm{K}$ and Hirakawa $\mathrm{K}$ : Significance of E-cadherin expression in triple-negative breast cancer. Br J Cancer 103: 249-255, 2010.

25 Kashiwagi S, Asano Y, Goto W, Takada K, Takahashi K, Hatano T, Tanaka S, Takashima T, Tomita S, Motomura H, Ohsawa M, Hirakawa K and Ohira M: Mesenchymal-epithelial Transition and Tumor Vascular Remodeling in Eribulin Chemotherapy for Breast Cancer. Anticancer Res 38: 401-410, 2018.

26 Cho KH, Yu SL, Cho DY, Park CG and Lee HY: Breast cancer metastasis suppressor 1 (BRMS1) attenuates TGF-beta1-induced breast cancer cell aggressiveness through downregulating HIF1alpha expression. BMC Cancer 15: 829, 2015.
27 Funahashi Y, Okamoto K, Adachi Y, Semba T, Uesugi M, Ozawa Y, Tohyama O, Uehara T, Kimura T, Watanabe H, Asano M, Kawano S, Tizon X, McCracken PJ, Matsui J, Aoshima K, Nomoto $\mathrm{K}$ and Oda Y: Eribulin mesylate reduces tumor microenvironment abnormality by vascular remodeling in preclinical human breast cancer models. Cancer Sci 105: 1334-1342, 2014.

28 Ueda S, Saeki T, Takeuchi H, Shigekawa T, Yamane T, Kuji I and Osaki A: In vivo imaging of eribulin-induced reoxygenation in advanced breast cancer patients: a comparison to bevacizumab. Br J Cancer 114: 1212-1218, 2016.

29 Sun LL, Song Z, Li WZ and Tang SY: Hypoxia facilitates epithelial-mesenchymal transition-mediated rectal cancer progress. Genet Mol Res 15, 2016. doi: 10.4238/gmr15048936. [Epub ahead of print]

30 Chen S, Chen JZ, Zhang JQ, Chen HX, Yan ML, Huang L, Tian YF, Chen YL and Wang YD: Hypoxia induces TWIST-activated epithelial-mesenchymal transition and proliferation of pancreatic cancer cells in vitro and in nude mice. Cancer Lett 383: 73-84, 2016.

31 Noman MZ, Desantis G, Janji B, Hasmim M, Karray S, Dessen $\mathrm{P}$, Bronte V and Chouaib S: PD-L1 is a novel direct target of HIF-1alpha, and its blockade under hypoxia enhanced MDSCmediated T cell activation. J Exp Med 211: 781-790, 2014.

32 Noman MZ, Janji B, Abdou A, Hasmim M, Terry S, Tan TZ, Mami-Chouaib F, Thiery JP and Chouaib S: The immune checkpoint ligand PD-L1 is upregulated in EMT-activated human breast cancer cells by a mechanism involving ZEB-1 and miR-200. Oncoimmunology 6: e1263412, 2017.

33 Kashiwagi S, Asano Y, Goto W, Takada K, Takahashi K, Noda S, Takashima T, Onoda N, Tomita S, Ohsawa M, Hirakawa K and Ohira M: Use of Tumor-infiltrating lymphocytes (TILs) to predict the treatment response to eribulin chemotherapy in breast cancer. PLoS One 12: e0170634, 2017.

Received March 5, 2018

Revised March 23, 2018

Accepted March 26, 2018 